\title{
Características produtivas e qualitativas de melão rendilhado adubado com nitrogênio e potássio
}

\author{
Matheus de C. Silva ${ }^{1}$, Tonny J. A. da Silva ${ }^{2}$,Edna M. Bonfim-Silva ${ }^{3} \&$ Lorraine do N. Farias $^{4}$ \\ ${ }^{1}$ ICAT/UFMT. Rondonópolis, MT. Fone: (66) 3410-4041. E-mail: matheus_gbi@hotmail.com \\ ${ }^{2}$ ICAT/UFMT. Rondonópolis, MT. Fone: (66) 3410-4041. E-mail: tonny.silva@pq.cnpq.br \\ ${ }^{3}$ ICAT/UFMT. Rondonópolis, MT. Fone: (66) 3410-4041. E-mail: embonfim@hotmail.com (Autor correspondente) \\ ${ }^{4}$ ICAT/UFMT. Rondonópolis, MT. Fone: (66) 3410-4041. E-mail: nascimentofarias@hotmail.com
}

\section{Palavras-chave:}

adubação de meloeiro

Cucumis melo

cantaloupe

cultivo protegido

\begin{abstract}
R E S U M O
O melão é uma das frutas frescas mais exportadas pelo Brasil com crescente área plantada no Estado de Mato Grosso. Em razão de se encontrar associada aos aspectos quantitativos e qualitativos do fruto, a adubação nitrogenada e a potássica são fatores de destaque na produção do meloeiro. Objetivou-se, através deste estudo, avaliar as características produtivas e qualitativas dos frutos de melão rendilhado cultivado em casa de vegetação em função de doses de nitrogênio e potássio. O estudo foi conduzido no período de abril a agosto de 2012 em delineamento experimental de blocos ao acaso, em esquema fatorial 5 x 5, com quatro repetições. As doses de nitrogênio foram de 0; 40, 80, 120 e $160 \mathrm{mg} \mathrm{dm}^{-3}$ e as de potássio corresponderam a 0, 80160 , 240 e $320 \mathrm{mg} \mathrm{dm}^{-3}$. O melão cultivado foi do tipo cantaloupe, híbrido Rafael. As características avaliadas foram produtividade total, espessura da polpa, teor de sólidos solúveis totais e acidez titulável. O nitrogênio promoveu aumento da produtividade e da qualidade dos frutos, de forma linear crescente enquanto as doses de potássio que promoveram os melhores resultados se situaram no intervalo de $240 \mathrm{a} 263,4 \mathrm{mg} \mathrm{dm}^{-3}$ influenciando de forma quadrática às variáveis estudadas.
\end{abstract}

Key words: fertilization of melon Cucumis melo cantaloupe protected cultivation

\section{Productivity and quality characteristics of nitrogen and potassium fertilized net melon}

\begin{abstract}
A B S T R A C T
Melon is one of Brazil's most exported fresh fruit and area under this crop is increasingly acreage in the state of Mato Grosso. Due to its association with quantitative and qualitative aspects of the fruit, nitrogen and potassium fertilization is a prominent factor in the production of melon plant. The objective of this study is to evaluate qualitative and productive characteristics of the net melon fruits, cultivated in a greenhouse, based on doses of nitrogen and potassium. The study was conducted from April to August 2012 in randomized block design, in a $5 \times 5$ factorial design with four replications. Nitrogen doses were $0,40,80,120$ and $160 \mathrm{mg} \mathrm{dm}^{-3}$ while potassium doses corresponded to: 0 ; $80 ; 160 ; 240$ and $320 \mathrm{mg} \mathrm{dm}^{-3}$. The cultivated melon was cantaloupe type, hybrid Rafael. The evaluated characteristics were overall productivity, pulp thickness, total soluble solids content and titratable acidity. The nitrogen promoted an increase in productivity and fruit quality in a linear way and the potassium doses that promoted the best results was situated in the range of 240 to $263.4 \mathrm{mg} \mathrm{dm}^{-3}$, responding quadratically to the studied variables.
\end{abstract}

\section{INTRODUÇÃo}

O meloeiro (Cucumis melo L.) pertence à família das Curcubitáceas, sendo uma olerícola muita apreciada e de grande popularidade no mundo; atualmente, é uma das frutas frescas mais exportadas pelo Brasil (Nascimento Neto et al., 2012).

O melão, além de promover a diversificação das atividades agrícolas, possui papel socioeconômico de grande importância nas regiões produtoras, contribuindo de forma significativa para a mudança do quadro social daqueles que têm na agricultura sua forma de sustento. A fruticultura é uma alternativa para inserção do pequeno produtor no cenário agrícola.
A produção em ambiente protegido possibilita outras vantagens, como a produção em períodos de entressafra, além de reduz os efeitos de fatores adversos externos como ventos, excesso ou escassez de chuvas e doenças, entre outros. Para se obtiver melhores resultados no cultivo de determinada espécie vegetal necessita-se, fundamentalmente, adaptá-la ao novo ambiente considerando conjuntamente a eficiência do uso da água, de nutrientes, fatores edafoclimáticos e técnicas de cultivo (Sandri et al., 2007).

Apesar da importância econômica da cultura do melão para o país, a produtividade desta cultura é bastante variável entre os produtores e, na maioria das vezes, baixa em relação ao potencial produtivo da cultura, o que sinaliza necessidade de pesquisas para definir as melhores tecnologias de manejo da 
cultura capazes de aumentar a produtividade e a qualidade dos frutos, permitindo que o fruto se torne mais competitivo nos mercados nacional e internacional.

No manejo do melão a reposição de nutrientes é uma das práticas de maior importância, proporcionando ganhos em produtividade e qualidade dos frutos. Dentre os nutrientes, a recomendação de adubação potássica e nitrogenada é bem diversificada na literatura; entretanto, a quantidade sugerida sofre grande variação de acordo com as condições edafoclimáticas da região, características genotípicas da cultura e forma e frequência de aplicação dos fertilizantes.

O cultivo de meloeiro em ambiente protegido tem respondido tanto à adubação nitrogenada (Queiroga et al., 2007) quanto à adubação potássica (Silva Júnior et al., 2010 e Nascimento Neto, 2011) com ganhos em produtividade e qualidade dos frutos de melão tipo cantaloupe.

Queiroga et al. (2007) salientaram que a adubação nitrogenada pode aumentar significativamente a produtividade e a qualidade de frutos de meloeiro, com salto em produtividade total de 34,14 t ha-1 sem aplicação de nitrogênio, para 46,50 tha ${ }^{-1}$ com aplicação da dose recomenda pelo autor, resultados que corroboram com Fontes et al. (2004).

No que concerne à adubação potássica, Viana et al. (2007) e Sousa et al. (2010) não encontraram diferenças significativas ao avaliar a produtividade de frutos de meloeiro sob a influência da adubação potássica. Esses resultados diferem dos obtidos por Sousa et al. (2005) que observaram não apenas ganhos em produtividade sobre o efeito isolado do potássio mas também a interação nitrogênio x potássio.

De acordo com Monteiro et al. (2006) as respostas das culturas constituem fontes valiosas de informações a serem utilizadas nos modelos de tomada de decisão permitindo a otimização do uso dos fatores envolvidos na produção. A falta de racionalização dos fertilizantes pela maioria dos produtores, além de aumentar o custo de produção, diminui o rendimento e qualidade dos frutos e ocasiona a contaminação do meio ambiente.

Diante da importância da adubação objetivou-se, com o presente estudo, avaliar as características quantitativas e qualitativas dos frutos de melão rendilhado cultivado em casa de vegetação, em função de doses de nitrogênio e potássio.

\section{Material e Métodos}

O experimento foi conduzido em casa de vegetação com estrutura metálica coberta com filme de polietileno e com sistema de refrigeração adiabático, no período de abril a agosto de 2012. O solo utilizado foi classificado como Latossolo Vermelho distrófico, de acordo com o método proposto pela EMBRAPA (2006), coletado em área com vegetação de cerrado na camada de $0-20 \mathrm{~cm}$ de profundidade e peneirado em malha de $2 \mathrm{~mm}$ para análises químicas e granulométricas e $4 \mathrm{~mm}$ para o preenchimento dos vasos plásticos com $15 \mathrm{dm}^{3}$ de solo.

$\mathrm{O}$ solo apresentava as seguintes características: $\mathrm{pH}(\mathrm{em}$ $\left.\mathrm{CaCl}_{2}\right)=4,1 ; \mathrm{Al}$ trocável $\left(\mathrm{cmol}_{\mathrm{c}} \mathrm{dm}^{-3}\right)=0,9 ; \mathrm{Ca}\left(\mathrm{cmol}_{\mathrm{c}} \mathrm{dm}^{-3}\right)$ $=0,2 ; \mathrm{Mg}\left(\mathrm{cmol}_{\mathrm{c}} \mathrm{dm}^{-3}\right)=0,1 ; \mathrm{P}($ Mehlich $)\left(\mathrm{mg} \mathrm{dm}^{-3}\right)=1,1 ; \mathrm{K}$ $\left(\mathrm{mg} \mathrm{dm}^{-3}\right)=22$; matéria orgânica $\left(\mathrm{g} \mathrm{dm}^{-3}\right)=12,8 ; \mathrm{V}(\%)=9,8$; $\mathrm{Zn}, \mathrm{Cu}, \mathrm{Fe}, \mathrm{Mn}, \mathrm{B}, \mathrm{S}\left(\mathrm{mg} \mathrm{dm}^{-3}\right)=0,8 ; 0,4 ; 161 ; 14,8 ; 0,20 ; 6,8$, respectivamente. Argila $\left(\mathrm{g} \mathrm{kg}^{-1}\right)=421$; Areia $\left(\mathrm{g} \mathrm{kg}^{-1}\right)=496$; Silte $\left(\mathrm{g} \mathrm{kg}^{-1}\right)=83$.

O delineamento experimental utilizado foi em blocos casualizados cujos tratamentos constituíram de um esquema em fatorial $5 \times 5$, com quatro repetições, correspondendo a cinco doses de nitrogênio $\left(0 ; 40 ; 80 ; 120\right.$ e $\left.160 \mathrm{mg} \mathrm{dm}^{-3}\right)$ e cinco doses de potássio $\left(0 ; 80 ; 160 ; 240\right.$ e $\left.320 \mathrm{mg} \mathrm{dm}^{-3}\right)$. Em cada bloco havia 25 parcelas experimentais que ocupavam uma área de $12,5 \mathrm{~m}^{2}$ e espaçamento de $1,0 \times 0,5 \mathrm{~m}$.

Realizou-se a calagem, com base na análise química do solo visando elevar a saturação por bases para $80 \%$ com o uso de calcário dolomítico. A umidade o solo no período de incubação do calcário foi mantida pelo método gravimétrico com $60 \%$ do volume máximo de retenção de água no solo.

A adubação de implantação da cultura foi realizada com $200 \mathrm{mg} \mathrm{dm}^{-3}$ de $\mathrm{P}_{2} \mathrm{O}_{5}$ na forma de superfosfato simples e o potássio foi aplicado conforme o tratamento de cada parcela experimental tendo como fonte o cloreto de potássio, ambos em dose única. A adubação nitrogenada foi parcelada em três aplicações (aos 15, 30 e 45 dias após a emergência - DAE). Cada unidade experimental recebeu a dose de nitrogênio de acordo com o tratamento sendo a ureia a fonte utilizada. A adubação com micronutrientes foi realizada segundo a recomendação de Sousa \& Lobato (2002).

O melão cultivado foi do tipo cantaloupe, híbrido Rafael, da Feltrin Sementes. Esse tipo de melão possui a casca rendilhada, polpa de coloração salmão e exala aroma característico quando maduro. A empresa obtentora das sementes relata que o fruto apresenta ciclo entre 60-70 dias, possui formato redondo, peso médio de 2,0-2,5 kg, além de boa aceitação comercial, rendilhamento fechado, boa conservação pós-colheita e bons teores de açúcares.

Para o monitoramento da temperatura e umidade relativa do ar no período experimental foi instalado, no interior da casa de vegetação, um termohigrômetro na altura do dossel das plantas. As médias registradas foram de $33,9{ }^{\circ} \mathrm{C}$ para temperatura máxima e $22,6^{\circ} \mathrm{C}$ para temperatura mínima enquanto os valores médios da máxima umidade relativa do ar foram de $91,9 \%$ e para mínima, de 54,3\%.

A irrigação foi manual e o volume de água utilizado para a irrigação por parcela experimental foi determinado pela equação de van Genuchten, utilizada conforme a determinação da curva de retenção de água no solo com amostras indeformadas de solo retiradas das unidades experimentais. Para que as plantas não sofressem estresse hídrico, sensores Irrigas foram instalados em todas as parcelas experimentais a $15 \mathrm{~cm}$ de profundidade realizando-se leituras diárias pela manhã. $\mathrm{O}$ momento de irrigar era determinado quando a tensão atingia $25 \mathrm{kPa}$ aplicando-se um volume de $800 \mathrm{~mL}$ de água em cada vaso.

O plantio foi realizado por meio da semeadura direta, no dia 21 de abril de 2012, utilizando-se cinco sementes por vaso e aos 12 DAE foi realizado o primeiro desbaste deixando-se três plantas por vaso e aos 20 DAE foi feito o segundo desbaste ficando apenas uma planta por vaso. 
O sistema de condução foi do tipo espaldeira vertical sendo implantadas ripas de madeira no sentido vertical na estrutura de metal da casa de vegetação com dois fios de arame liso na horizontal, o primeiro disposto a $0,50 \mathrm{~m}$ acima da borda do vaso e o segundo arame a 1,10 $\mathrm{m}$ acima do primeiro.

Os ramos laterais entre o primeiro e o segundo arames foram mantidos para florescimento e frutificação. A desbrota foi feita nos ramos originados fora do intervalo entre $10^{\circ}$ e $18^{\circ}$ internódio. Quando a haste principal ultrapassou o segundo fio de arame a poda apical foi realizada. Deixou-se um fruto por planta e, quanto às brotações laterais com fruto, realizouse a poda após a primeira folha posterior ao fruto; para sua sustentação os frutos foram envolvidos em redes plásticas, penduradas nos fios de arame do sistema de condução.

A polinização foi manual, coletando-se flores masculinas e levando-as em contato direto com as flores femininas e hermafroditas; após a fixação dos frutos, raleios foram efetuados sempre que necessário para deixar um fruto por planta.

A colheita teve início no dia 5 de julho de 2012 (70 DAE) e o momento da colheita foi determinado quando apresentava a camada de abscisão do pendúnculo.

Para avaliar a produtividade total realizou-se a pesagem individual dos frutos em balança de precisão os quais foram classificados como frutos comerciais, os não deformados com rendilhamento em toda a casca e ao redor do pedúnculo e com peso superior a $0,550 \mathrm{~kg}$, de acordo com Filgueiras et al. (2000) sendo o desempenho produtivo da planta determinado pela produção em kg planta ${ }^{-1}$.

O fruto foi divido em três partes iguais para análises químicas e para medida da espessura da polpa com auxílio de um paquímetro. Visando determinar a qualidade dos frutos avaliou-se o teor de sólidos solúveis totais por meio da retirada de amostras da polpa dos frutos com a utilização de refratômetro obtendo-se os valores em ${ }^{\circ}$ Brix (Coelho et al., 2003). Em seguida, analisou-se a acidez titulável total de acordo com o método proposto pelo IAL (2005).

Para a análise estatística das variáveis quantitativas e qualitativas dos frutos do meloeiro os tratamentos que possuíam a combinação com $0 \mathrm{mg} \mathrm{dm}^{-3}$ de potássio foram excluídos pela ausência de frutos nas plantas de melão com os respectivos tratamentos: $0 \mathrm{~N} 0 \mathrm{~K} ; 40 \mathrm{~N} 0 \mathrm{~K} ; 80 \mathrm{~N} 0 \mathrm{~K} ; 120 \mathrm{~N} 0 \mathrm{~K}$ e $160 \mathrm{~N} 0 \mathrm{~K}$.

Os resultados das variáveis foram submetidos à análise de variância e regressão até $5 \%$ de probabilidade. Todas as análises estatísticas foram realizadas com o auxílio do aplicativo Sisvar (Ferreira, 2008).

\section{Resultados e Discussão}

De acordo com a síntese da análise de variância verificase que as doses de nitrogênio e potássio influenciaram isoladamente nas características produtivas e qualitativas de melão rendilhado (Tabela 1 ).

A produção total do melão rendilhado foi influenciada positivamente tanto pelas doses de nitrogênio quanto pelas doses de potássio, de forma linear proporcionado pelos acréscimos dos teores no solo dos nutrientes estudados. A
Tabela 1. Síntese da análise de variância para os rendimentos médios de produção $\left(\mathrm{kg} \mathrm{planta}^{-1}\right)$, espessura da polpa (mm), ${ }^{\circ}$ Brix e acidez titulável (\%) de melão rendilhado cantaloupe híbrido Rafael em função de doses de nitrogênio e potássio

\begin{tabular}{|c|c|c|c|c|c|}
\hline \multirow[b]{2}{*}{ FV } & \multirow[b]{2}{*}{ GL } & \multicolumn{4}{|c|}{ Quadrado médio } \\
\hline & & $\begin{array}{l}\text { Produção } \\
\text { (kg planta') }\end{array}$ & $\begin{array}{l}\text { Espessura } \\
\text { da polpa } \\
\text { (mm) }\end{array}$ & ${ }^{0}$ Brix & $\begin{array}{c}\text { Acidez } \\
\text { titulável } \\
\text { total (\%) }\end{array}$ \\
\hline Doses de N & 4 & 0,597572 ** & 80,105583 *** & $6,803083^{\star *}$ & 0,020986 *** \\
\hline Doses de K & 3 & 0,214118 * & 80,501500 ** & $39,920167^{\star \star \star}$ & $0,021344^{* \star \star}$ \\
\hline$N^{*} K$ & 12 & $0,067660 \mathrm{~ns}$ & $15,150250 \mathrm{~ns}$ & 1,793639 ns & 0,004848 ns * $^{*}$ \\
\hline Bloco & 2 & 0,053770 & 56,616667 & 0,631167 & $0,003662^{\star \star \star}$ \\
\hline Erro & 38 & 0,060559 & 14,078596 & 1,545026 & $0,002720^{* \star \star \star}$ \\
\hline Média Geral & & 1,268865 & 28,701667 & 8,431667 & $0,277167^{* * *}$ \\
\hline CV (\%) & & 19,39 & 13,07 & 14,74 & 18,82 \\
\hline
\end{tabular}

${ }^{*},{ }^{* *},{ }^{* * *}$ e, ns Significativo a $0,1,1$ e 0,05 de probabilidade, pelo teste $F$, respectivamente $e$ ${ }^{n s}$ Não significativo pelo teste $F$

dose máxima de nitrogênio elevou a produção em 54,65\% quando comparada à ausência da adubação nitrogenada confirmando a importância desse nutriente na produção do meloeiro, que alcançou uma produção de 1,541 e $1,387 \mathrm{~kg}$ planta $^{-1}$ para o uso da maior dose de nitrogênio e potássio (Figura 1A e 1B) respectivamente, podendo-se deduzir que a adubação nitrogenada é mais eficiente em termos produtivos que a adubação potássica, especialmente em doses iguais às utilizadas neste experimento.

Diversos autores (Faria et al., 2000; Coelho et al., 2003) obtiveram aumento do número e da massa média de fruto e, consequentemente, da produtividade, com a elevação das doses de nitrogênio corroborando com os resultados deste presente estudo.

Em seu estudo, Andriolo et al. (2005) estimaram que as concentrações em solução nutritiva de 273 e $351 \mathrm{mg} \mathrm{L}^{-1}$, respectivamente de nitrato e de potássio, resultariam em produção máxima de aproximadamente $1,997 \mathrm{~kg}$ planta-1 ${ }^{-1}$ para o meloeiro cantaloupe híbrido Torreon cultivado em substrato comercial com dois frutos por planta.

Queiroga et al. (2007) e Fontes et al. (2004) relataram o benefício de nitrogênio no peso médio de frutos do meloeiro e encontraram respostas quadráticas para as doses de nitrogênio estudadas. O primeiro autor alcançou uma produção de frutos comerciais de $1,312 \mathrm{~kg}$ planta $^{-1}$ para o melão do grupo Cantalupensis com aplicação de $309,7 \mathrm{~kg} \mathrm{ha}^{-1}$ de nitrogênio e com resultados semelhantes para o segundo autor, que registrou produção equivalente a $1,350 \mathrm{~kg}_{\text {planta }}{ }^{-1}$ com o híbrido Trusty (grupo Cantalupensis) no uso da dose estimada de $312 \mathrm{~kg} \mathrm{ha}^{-1}$ de nitrogênio, mas Queiroga et al. (2011) relataram, ao avaliar o efeito de doses de nitrogênio sob a produtividade total do melão tipo cantaloupe híbrido Paraná, que o maior valor de massa média do fruto foi de $1,340 \mathrm{~kg}$, obtido no uso da maior dose, que corresponde a $177,8 \mathrm{~kg} \mathrm{ha}^{-1}$ de nitrogênio com incremento na massa média do fruto entre a menor $\left(0 \mathrm{~kg} \mathrm{ha}^{-1} \mathrm{de} \mathrm{N}\right)$ e a maior dose de $6,72 \%$, com resposta linear para os tratamentos aplicados.

Para os tratamentos com combinações de doses de nitrogênio e potássio as parcelas experimentais que receberam 


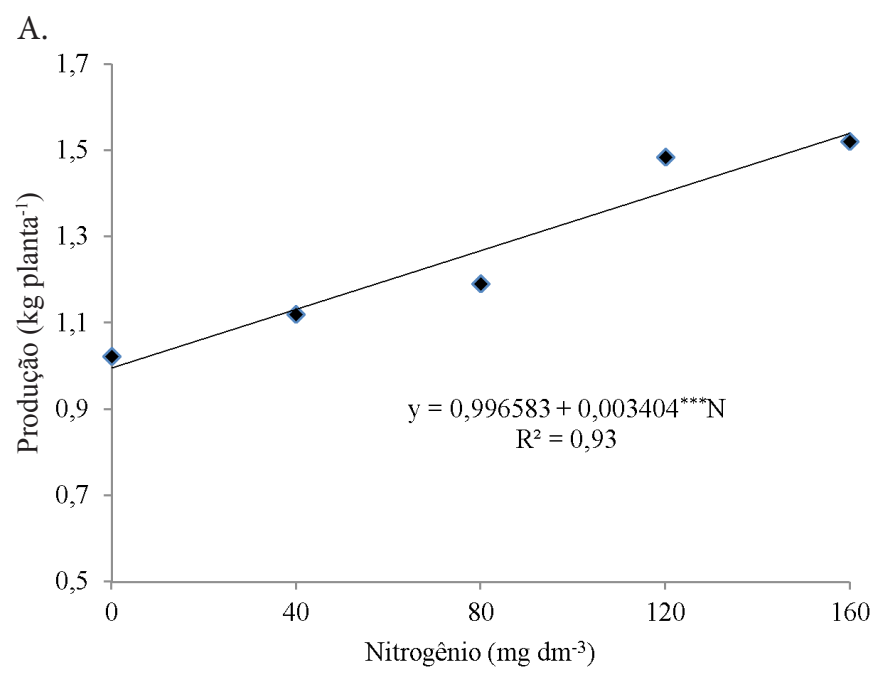

B.

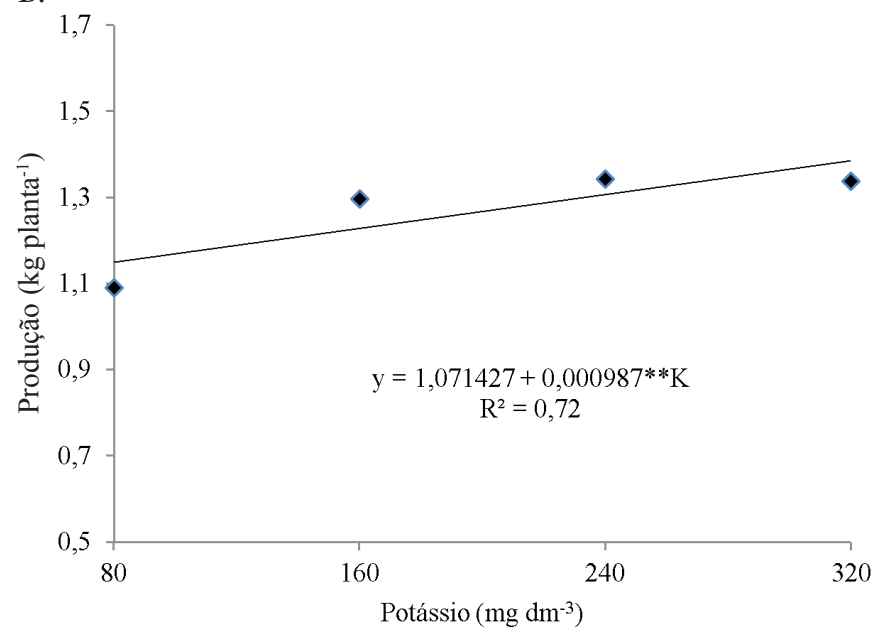

*** Significativo a 0,001 de probabilidade; ** Significativo a 0,01 de probabilidade

Figura 1. Produção de melão cantaloupe híbrido Rafael em função de doses de nitrogênio (A) e potássio (B)

doses inferiores a $120 \mathrm{mg} \mathrm{dm}^{-3}$ de nitrogênio produziram frutos de melão classificados como não comerciais em virtude de não atenderem às exigências mercadológicas no requisito grau de rendilhamento porém o peso mínimo ( $>0,5 \mathrm{~kg})$ foi alcançado em todos os tratamentos (Figura 2). A carência de nitrogênio ocasiona frutos pequenos (Holanda et al., 2008) e pouco reticulados (Silva Júnior et al., 2010).

$\mathrm{O}$ aumento do peso médio dos frutos do meloeiro com a elevação das doses de potássio proporcionou incremento de

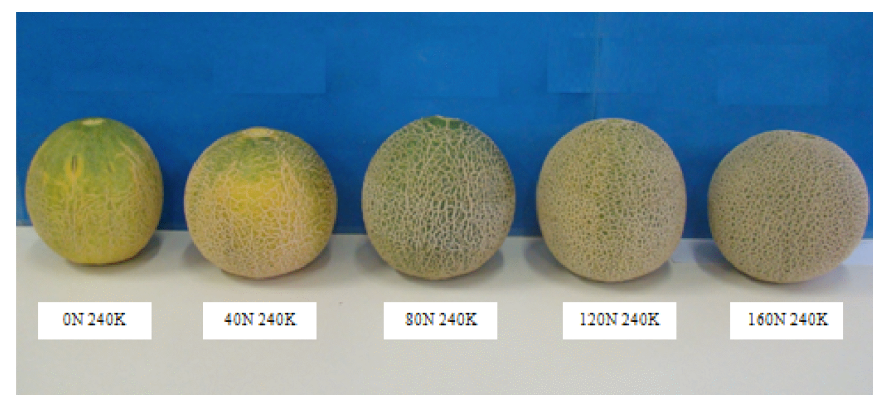

Figura 2. Efeito isolado da adubação com nitrogênio na massa, redilhamento e formato de frutos de melão cantaloupe híbrido Rafael
$17,06 \%$ na produtividade da cultura em comparação com o uso da menor dose de potássio $\left(80 \mathrm{mg} \mathrm{dm}^{-3}\right)$.

Referente ao efeito isolado do potássio, os frutos de melão não apresentaram rendilhamento em toda a superfície (Figura 3) e apesar do formato do fruto ser algo inerente à genética e a fatores ambientais menos marcantes (Paiva et al., 2008), podese observar que a ausência da adubação nitrogenada, além de influenciar o rendilhamento do fruto também alterou seu formato sendo as medidas do diâmetro transversal do fruto inferiores às do diâmetro longitudinal, influenciando de forma significativa as características fenotípicas da cultivar estudada. Mencionadas características promovem a desvalorização do produto por não se enquadrarem como frutos comerciais ocasionando em perda de produtividade. Todos os formatos são aceitos pelo mercado (Pádua et al., 2003); no entanto, os de formato esférico são os mais adequados na disposição em embalagens e no transporte.

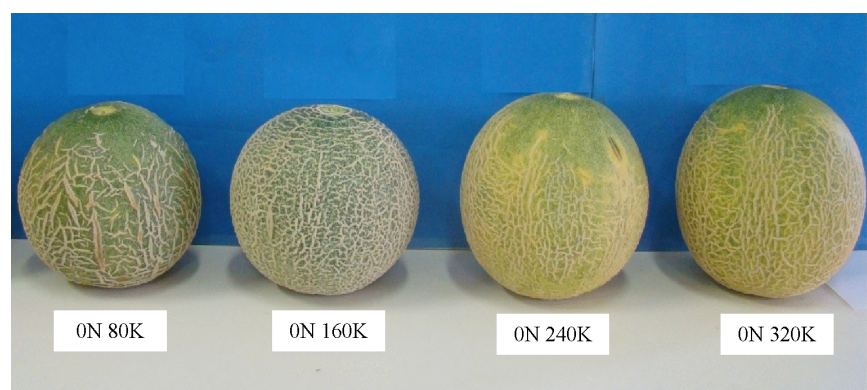

Figura 3. Efeito isolado da adubação com potássio na massa, redilhamento e formato de frutos de melão cantaloupe híbrido Rafael

Quanto à adubação potássica, Silva Júnior et al. (2010) observaram respostas lineares quando avaliaram a produtividade do melão cantaloupe fertirrigado com doses de potássio. No entanto, Viana et al. (2007) e Sousa et al. (2010) não evidenciaram efeitos significativos de doses de potássio no meloeiro.

Para a espessura da polpa de melão rendilhado observouse efeito isolado para doses de nitrogênio e potássio, a análise de regressão revelou ajuste ao modelo linear de regressão para nitrogênio e quadrático para potássio.

A maior espessura de polpa foi observada pelo uso do nitrogênio com espessura de $31,83 \mathrm{~mm}$ para dose de 160 $\mathrm{mg} \mathrm{dm}{ }^{-3}$ e testemunha com média de $25,57 \mathrm{~mm}$ obtendo-se um incremento de $23,46 \%$ (Figura $4 \mathrm{~A}$ ). O ponto de máxima proporcionado pelo potássio foi estimado em $30,70 \mathrm{~mm}$ para a dose de $240 \mathrm{mg} \mathrm{dm}^{-3}$ (Figura 4B). A diferença entre o valor máximo da espessura da polpa proporcionada pelo nitrogênio e pelo potássio foi de $1,13 \mathrm{~mm}$, valor pouco significativo.

Costa \& Pinto (1977) asseguram que o fruto ideal deve ter polpa espessa e cavidade interna pequena, atributos que conferem ao fruto melhor resistência ao transporte e maior durabilidade pós-colheita. A maior espessura da polpa é desejável pois aumenta o peso e a parte comestível melhorando a qualidade do fruto (Coelho et al., 2003). Purquerio \& Cecílio Filho (2005) cultivaram melão cantaloupe híbrido Bônus n. ${ }^{\circ} 2 \mathrm{e}$ observaram que o aumento do número de frutos por planta de dois para quatro reduziu a espessura da polpa de 31 para $29 \mathrm{~mm}$. 
A.

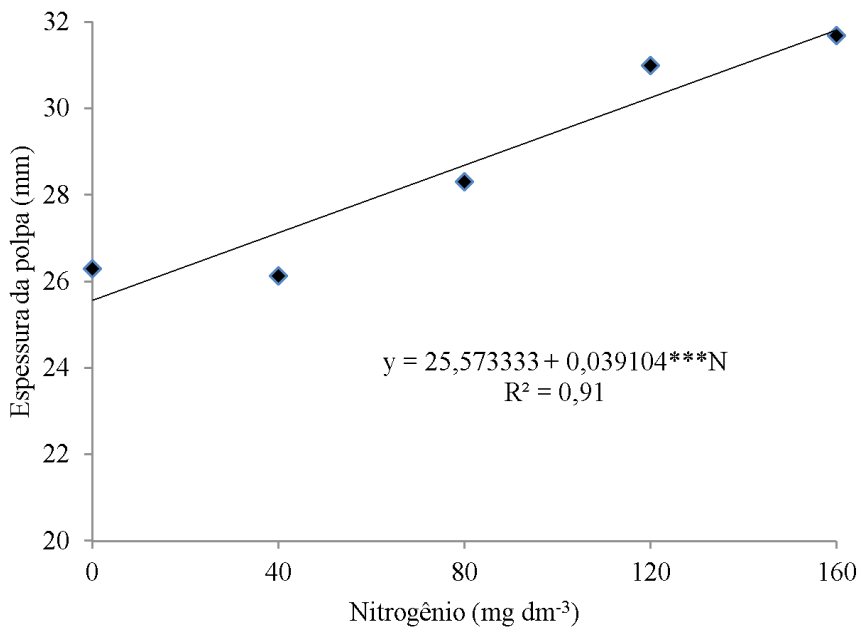

B.

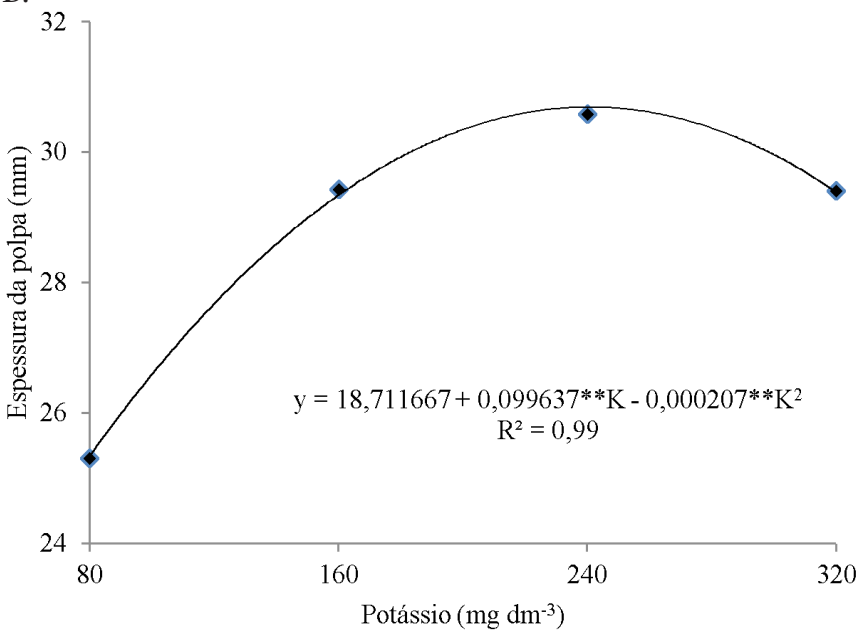

*** Significativo a 0,001 de probabilidade; ** Significativo a 0,01 de probabilidade

Figura 4. Espessura da polpa dos frutos do melão cantaloupe híbrido Rafael em função de doses de nitrogênio (A) e potássio (B)

No experimento realizado por Queiroga et al. (2007) resposta linear para a espessura da polpa para os melões do grupo Cantalupensis também foi encontrada com aumento na dose de nitrogênio com ensaio em casa de vegetação proporcionando um aumento da espessura da polpa de 33,69 para 39,63 mm, quando comparadas a maior dose $\left(540 \mathrm{~kg} \mathrm{ha}^{-1}\right)$ e a ausência de adubação. Folegatti et al. (2004) registraram que a espessura da polpa diminui para as doses 0 ou 12 g planta $^{-1} \mathrm{e}$ aumenta com os valores de doses intermediários ( 6 ou $<12 \mathrm{~g}$ planta $^{-1}$ ) e para Silva Júnior et al. (2010) a equação se ajustou ao modelo quadrático de regressão com ponto de mínimo observado.

Os efeitos dos níveis de nitrogênio e de potássio estudados sobre o teor e sólidos solúveis totais ocorreram de forma isolada; entretanto, com efeito linear e quadrático para o nitrogênio e potássio, respectivamente (Figura 5A e 5B).

Observou-se ajuste ao modelo linear de regressão para o teor de sólidos solúveis totais na medida em que ocorreu o aumento das doses de nitrogênio obtendo-se acréscimo estimado em $1,86^{\circ}$ Brix quando comparado a maior dose de nitrogênio com
A.

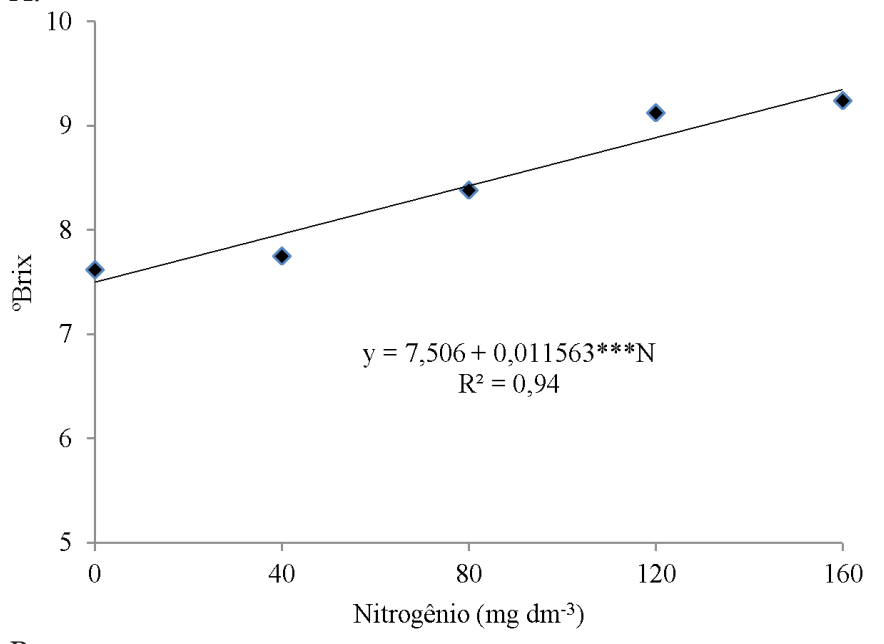

B.

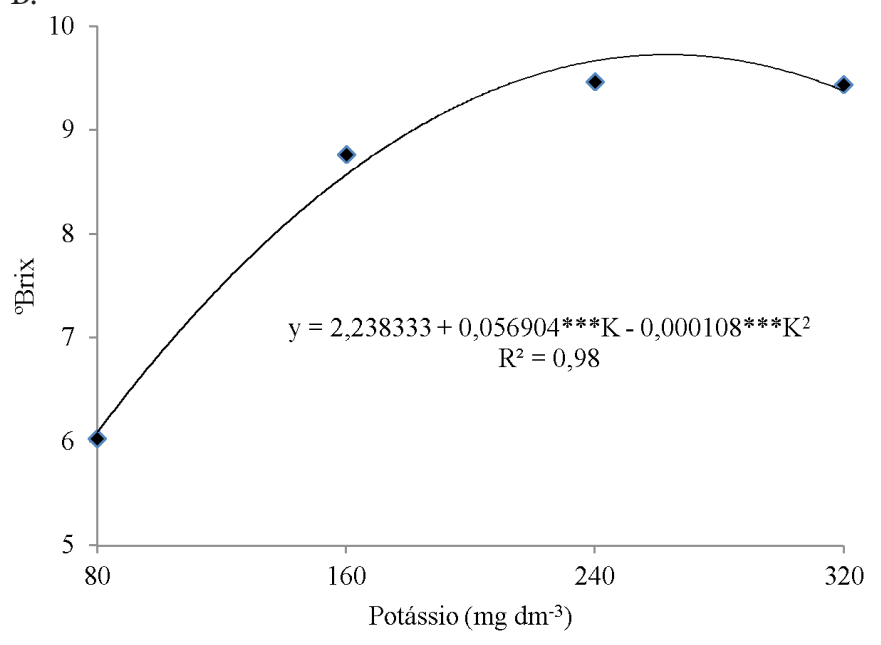

*** Significativo a 0,001 de probabilidade

Figura 5. ${ }^{\circ}$ Brix dos frutos de melão cantaloupe híbrido Rafael em função de doses de nitrogênio (A) e potássio (B)

a ausência da adubação nitrogenada indicando que doses mais elevadas de nitrogênio poderiam aumentar o teor de sólidos solúveis totais dos frutos de melão cantaloupe, que alcançou valor máximo dentro do intervalo de doses de nitrogênio utilizada, de $9,36^{\circ}$ Brix. Resultado semelhante foi observado por Queiroga et al. (2007) em estudo de dois híbridos de melão (tipo cantaloupe e charentais), ao responderam de forma linear com maior média de $9,99^{\circ}$ Brix, na dose de nitrogênio de $540 \mathrm{~kg} \mathrm{ha}^{-1}$.

Nascimento Neto et al. (2012) avaliaram doses de nitrogênio para o melão amarelo e constataram ajuste ao modelo quadrático de regressão para o teor de sólido solúvel em função dos tratamentos aplicados, enquanto Faria et al. (2000) observaram diferenças significativas no teor de sólidos solúveis totais do fruto do meloeiro mas somente na ausência de nitrogênio. Alguns autores (Purqueiro \& Cecílio Filho, 2005; Queiroga et al., 2011) relatam que o nitrogênio não influenciou de forma significativa essa variável, resultados que divergem dos verificados no presente estudo e reafirmam que a dose recomendada para a cultura do melão é influenciada tanto pela cultivar quanto pelo manejo da adubação adotado. 
Quanto ao potássio, o máximo valor de sólidos solúveis totais de $9,73{ }^{\circ}$ Brix foi obtido com a aplicação de $263,44 \mathrm{mg}$ $\mathrm{dm}^{-3}$ de potássio (Figura 5B). Nascimento Neto (2011) verificou que o excesso de potássio no solo aplicado via fertirrigação diminuiu o teor de sólidos solúveis totais dos frutos de melão amarelo híbrido Gold Mine, com ajuste ao modelo quadrático de regressão em que o máximo valor de sólidos solúveis totais foi de $11^{\circ}$ Brix com uma dose de potássio de $253,88 \mathrm{~kg} \mathrm{ha}^{-1}$. Sobre o efeito isolado do nitrogênio ou como o do potássio, os melhores tratamentos proporcionaram aos frutos nível de doçura acima de $9^{\circ}$ Brix, que é o mínimo estabelecido pelas normas internacionais (Silva et al., 2008).

Verifica-se efeito isolado para nitrogênio e potássio na avaliação da acidez titulável total ajustando-se ao modelo quadrático de regressão. O ponto de mínima foi estimado em 0,24 e 0,25\% de acidez titulável total nas doses de 33 e 121,67 $\mathrm{mg} \mathrm{dm}^{-3}$ de nitrogênio e potássio, respectivamente (Figura $6 \mathrm{~A}$; Figura 6B). As médias de acidez titulável total encontradas no presente ensaio se mantiveram dentro do intervalo proposto por Mendlinger \& Pastenak (1992) para melões em geral cujas quantidades de ácido cítrico variam de 0,05 a $0,35 \%$. Segundo

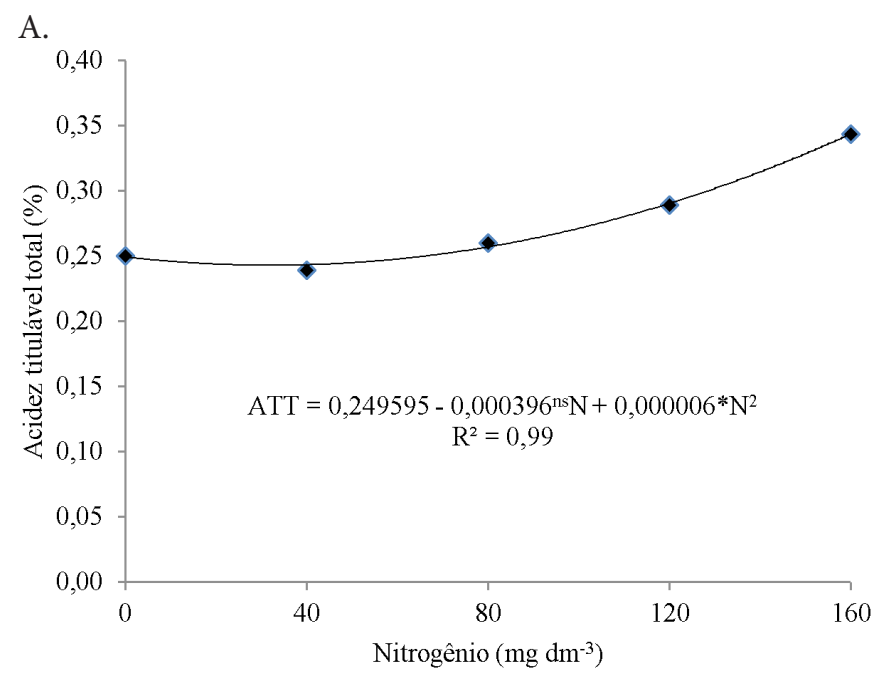

B.

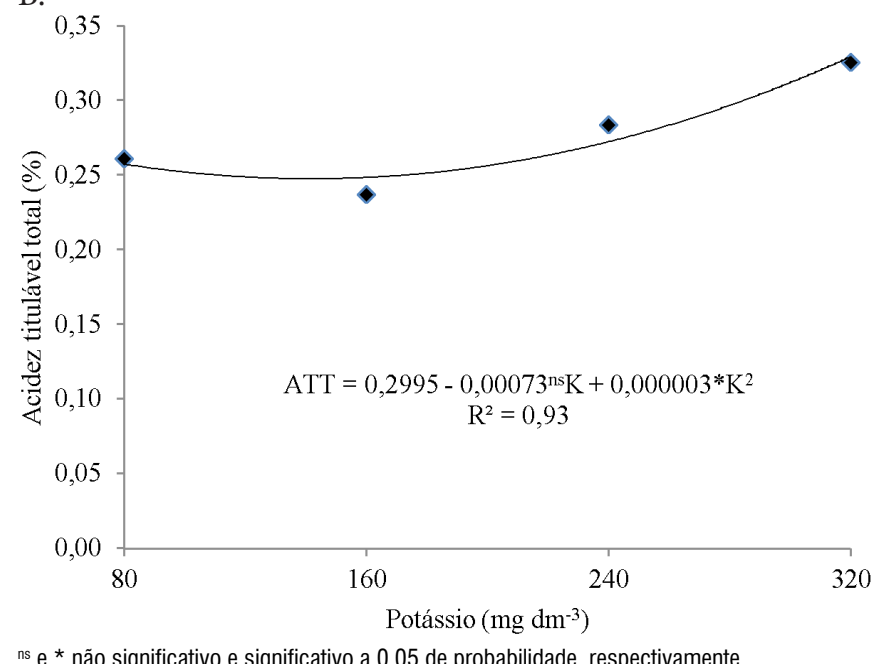

${ }^{\text {ns }} e^{*}$ não significativo e significativo a 0,05 de probabilidade, respectivamente

Figura 6. Acidez titulável total dos frutos de melão cantaloupe híbrido Rafael em função das doses de nitrogênio $(A)$ e potássio $(B)$
Villanueva et al. (2004) no meloeiro as modificações no sabor são devidas às alterações nos compostos aromáticos, ácidos orgânicos e açúcares solúveis.

As médias de acidez titulável total observadas no presente estudo, foram superiores aos valores encontrados por Santos et al. (2011), para genótipos de melão amarelo que, normalmente, possuem sabor e aroma considerados inferiores aos dos melões do grupo Cantalupensis.

Coelho et al. (2003) e Queiroga et al. (2007) observaram aumento linear da acidez titulável total com o incremento de doses de nitrogênio. Purqueiro \& Cecílio Filho (2005) relataram que esse tipo de resposta pode ser atribuído ao aumento na atividade metabólica da planta promovido pelo nitrogênio, retardando a senescência da planta, com reflexos no grau de amadurecimento dos frutos porém Fernandes \& Grassi Filho (2003), não observaram efeito significativo para essa variável no uso de nitrogênio e potássio.

\section{Conclusões}

1. A adubação nitrogenada e a potássica promovem aumento na produção de melão cantaloupe de forma linear com resultados mais expressivos para adubação nitrogenada.

2. Para as variáveis qualitativas, a adubação com nitrogênio influencia de forma linear, enquanto a dose de potássio promove os melhores resultados com as doses que se situam no intervalo de 240 a $264 \mathrm{mg} \mathrm{dm}^{-3}$.

3. A acidez titulável total é influenciada pela adubação com nitrogênio e potássio de forma quadrática com ponto de mínima nas doses de nitrogênio e potássio de 33 e 121,67 $\mathrm{mg} \mathrm{dm}^{-3}$, respectivamente.

\section{Literatura Citada}

Andriolo, J. L.; Luz, G. L.; Bortolotto, O. C.; Godoi, R. S. Produtividade e qualidade de frutos de meloeiro cultivado em substrato com três doses de solução nutritiva. Ciência Rural, v.35, p.781-787, 2005.

Coelho, E. L.; Fontes, P. C. R.; Finger, F. L. Cardoso, A. A. Qualidade do fruto de melão rendilhado em função de doses de nitrogênio. Bragantia, v.62, p.173-178, 2003.

Costa, C. P.; Pinto C. A. B. P. Melhoramento de hortaliças. Piracicaba: ESALQ, 1977.319p.

EMBRAPA - Empresa Brasileira De Pesquisa Agropecuária. Centro Nacional de Pesquisa de Solos. Sistema brasileiro de classificação de solos. 2.ed. Rio de Janeiro; EMBRAPA, 2006. 306p.

Faria, C. M. B.; Costa, N. D.; Pinto, J. M.; Brito, L. T. de L.; Soares, J. M. Níveis de nitrogênio por fertirrigação e densidade de plantio na cultura do melão em um Vertissolo. Pesquisa Agropecuária Brasileira, v.35, p.491-495, 2000.

Fernandes, A. L.; Grassi Filho, H. Manejo da fertirrigação nitrogenada e potássica na cultura do melão rendilhado (Cucumis melo reticulatos Naud). Irriga, v.8, p.178-190, 2003.

Ferreira, D. F. SISVAR: um programa para análises e ensino de estatística. Revista Symposium, v.6, p.36-41, 2008. 
Filgueiras, H. A. C.; Menezes, J. B.; Alves, R. E.; Costa, F. V.; Pereira, L. S. E.; Gomes Júnior, G. Colheita e manuseio em pós colheita. In: Alves, R. E. (Org.) Melão: Pós-colheita. Brasília: Embrapa Comunicação para transferência de Tecnologia, 2000. cap.3, p.23-40.

Folegatti, M. V.; Vásquez, M. A. N.; Dias, N. S.; Sousa, V. F. Qualidade física do melão fertirrigado com diferentes doses de potássio e lâminas de irrigação em gotejamento superficial e subsuperficial. Irriga: Revista Brasileira de Irrigação e Drenagem, v.9, p.52-61, 2004.

Fontes, P. C. R.; Coelho, E. L.; Cardoso, A. A.; Finger, F. L. Produtividade do melão rendilhado em ambiente protegido e no campo, em função de doses de nitrogênio. Bioscience Journal, v.20, p.15-20, 2004.

Holanda, J. S. de; Silva, R. R. da; Freitas, de A. D. de. Fertilidade do solo, nutrição e adubação do meloeiro. In: Sobrinho, R. B.; Guimarães, J. A.; Freitas, J. de A. D. de; Terao, D. (Org.). Produção integrada de melão. Fortaleza: Embrapa Agroindústria Tropical, 2008. p.127-138.

IAL - Instituto Adolfo Lutz. Métodos físico-químicos para análise de alimentos. 4.ed. Brasília: IAL, 2005. 1018p.

Mendlinger, S.; Pastenak, D. Effect of time, salination of flowering, yield and quality factors in melon, Cucumis melo L. Journal of the American Society for Horticultural Science, v.67, p.529-534, 1992.

Monteiro, R. O. C.; Colares, D. S.; Costa, R. N. T.; Leão, M. C. S.; Aguiar, J. V. A. Função de resposta do meloeiro a diferentes lâminas de irrigação e doses de nitrogênio. Horticultura Brasileira, v.24, p.455-459, 2006.

Nascimento Neto, J. R. Formas de aplicação e doses de nitrogênio e potássio no cultivo do meloeiro amarelo. Ceará: UFC, 2011. 77p. Tese Doutorado

Nascimento Neto, J. R; Bomfim, G. V.; Azevedo, B. M.; Viana, T. V. A.; Vasconcelos, D. V. Formas de aplicação e doses de nitrogênio para o meloeiro amarelo no litoral do ceará. Irriga, v.17, p.364-375, 2012.

Pádua, J. G.; Braz L. T.; Banzatto, D. A.; Gusmão, S. A. L. Net melon cultivars productivity under different cultivation systems, during summer and winter. Acta Horticulturae, v. 607, p.83-89, 2003.

Paiva, W. O. de; Marques, G. V.; Mesquita, J. B. R.; Dantas, R. de S.; Freitas, F. W. A. de. Qualidade e conservação de frutos de melão Amarelo em dois pontos de colheita. Revista Ciência Agronômica, v.39, p.70-76, 2008.

Purqueiro, L. F. V.; Cecílio Filho, A. B. Concentração de nitrogênio na solução nutritiva e número de frutos sobre a qualidade de frutos de melão. Horticultura Brasileira, v.23, p.831-836, 2005.
Queiroga, F. M.; Costa, S. A. D.; Pereira, F. H. F.; Maracajá, P. B.; Sousa Filho, A. L. Efeito de doses de nitrogênio na produção e qualidade de frutos de melão gália. Revista Verde de Agroecologia e Desenvolvimento Sustentável, v.6, p.96-100, 2011.

Queiroga, R. C. F; Puiatti, M.; Fontes, P. C. R.; Cecon, P. R.; Finger, F. L. Influência de doses de nitrogênio na produtividade e qualidade do melão Cantalupensis sob ambiente protegido. Horticultura Brasileira, v.25, p.550556, 2007.

Sandri, D.; Rinaldi, M.; Souza, M. R. de.; Oliveira, H. F. E. de; Teles, L. M. Desenvolvimento e qualidade do melão cultivado no sistema hidropônico sob diferentes substratos e formato do leito de cultivo. Irriga, v.12, p.156-167, 2007.

Santos, M. F.; Costa, C. C.; Oliveira, E. M.; Barbosa, J. W. S. Avaliação de genótipos de melão amarelo em Paulista. Tecnologia \& Ciência Agropecuária, v.5, p.1-6, 2011.

Silva, E. de O.; Alves, R. E.; Santos, E. C. dos. Colheita e pós-colheita na produção integrada de melão. In: Braga Sobrinho, R.; Guimarães, J. A.; Freitas, J. de A. D. de; Terao, D. (org.). Produção integrada de melão. Fortaleza: Embrapa Agroindustria Tropical, 2008. p.273-284.

Silva Júnior, M. J. da; Duarte S. N.; Oliveira, F. de. A. de; Medeiros, J. F. de; Indalécio Dutra, I. Resposta do meloeiro à fertigação controlada através de íons da solução do solo: Parâmetros produtivos. Revista Brasileira de Engenharia Agrícola e Ambiental, v.14, p.723-729, 2010.

Sousa, A. E. C.; Bezerra, F. M. L.; Sousa, C. H. C. Produtividade do meloeiro sob lâmina de irrigação e adubação potássica. Engenharia Agrícola, v.30, p.271-278, 2010.

Sousa, D. M. G.; Lobato, E. Correção da acidez do solo. In: Sousa, D. M. G.; Lobato, E. Cerrado: Correção do solo e adubação. Embrapa Planaltina, 2002. 416p.

Sousa, V. F. de; Coelho, E. F.; Souza, V. A. B. de; Holanda Filho, R. S. F. de. Efeitos de doses de nitrogênio e potássio aplicadas por fertirrigação no meloeiro. Revista Brasileira de Engenharia Agrícola e Ambiental, v.9, p.210-214, 2005.

Viana, T. V. A.; Sales, I. G. M.; Sousa, V. F.; Azevedo, B. M.; Furlan, R. A.; Costa, S. C. Produtividade do meloeiro fertirrigado com potássio em ambiente protegido. Horticultura Brasileira, v.25, p.460-463, 2007.

Villanueva, M. J.; Tenório, M. D.; Esteban, M. A.; Mendonza, $\mathrm{M}, \mathrm{C}$. Compositional changes during ripening of two cultivars of muskmelon fruits. Food Chemistry, v.87; p.179-185, 2004. 